Sonia Montero Gálvez

DOI: $10.4312 / v h .22 .1 .37-58$

Columbia University, Nueva York

\title{
Los nombres escuetos y el artículo ø
}

Palabras clave: nombres escuetos, continuo/discontinuo, singular/plural, valor predicativo, valor referencial, valor cuantificador, expresión nominal sin determinante, artículo $\emptyset$, enfoque contrastivo.

\section{Introducción}

Actualmente, en la enseñanza de segundas lenguas se suele reconocer la necesidad de abordar los contenidos gramaticales de una forma explícita en el aula. Sin embargo, satisfacer esta necesidad es una tarea sumamente compleja porque la gramática no es un puzzle cuyas piezas puedan llevarse paulatinamente al aula confiando en que cada vez que se coloca una en su lugar equivale a un contenido asimilado; sino que es un organismo vivo (o una máquina perfecta) cuyos componentes están tan interrelacionados entre sí que no pueden funcionar de forma aislada e independiente ya que requieren la constante complicidad e interacción del resto para cumplir adecuadamente su función. Digo esto porque, en la enseñanza explícita de la gramática, nos vemos obligados a obviar o minimizar la fuerza de su naturaleza orgánica para presentarla como si fuera un puzzle, focalizando nuestra atención en uno o dos de sus componentes como si éstos constituyeran por sí mismos todo un organismo (o todo el engranaje de una máquina). Ésta es, sin duda, la principal dificultad a la que nos enfrentamos quienes apostamos por la enseñanza explícita de la gramática.

En principio, los planes curriculares de los centros de enseñanza y los manuales (y materiales) didácticos pueden contribuir enormemente a facilitar el camino a profesores y alumnos, pues no sólo sirven a modo de guía o mapa para saber de dónde venimos y adónde vamos en el laberinto de una gramática 
despedazada, sino que también nos marcan el recorrido por etapas, nos indican los lugares de imprescindible o recomendable visita y, en algunas ocasiones, hasta nos sugieren aventuras por zonas poco exploradas. Sin embargo, hay ciertas regiones a las que muchos profesores no nos aventuraríamos si no fuera por la insistencia o imperiosa necesidad de los alumnos en conocerlas. Según mi experiencia como profesora de E/LE, una de estas regiones es la relativa al uso y significado de los llamados 'nombres escuetos' (es decir, las expresiones constituidas por nombres comunes sin artículo ni determinante), cuyo conocimiento puede servir de gran ayuda de cara a la exploración de otros terrenos contiguos como son los relativos a las expresiones nominales introducidas por los artículos el/la/los/las y un/una/unos/unas.

\section{El enfoque contrastivo como punto de partida}

En El artículo en español (Castalia, 2011), la profesora Yuko Morimoto presenta el uso de los llamados 'nombres escuetos' y el de las expresiones nominales introducidas por el/la/los/las y un/a/os/as en contraste con sus equivalentes en otras lenguas románicas, germánicas, eslavas, escandinavas, orientales, etc. de manera que ilustra muy bien hasta qué punto pueden diferir los diferentes sistemas gramaticales en los que se basan las diferentes lenguas. A propósito del artículo, Morimoto dice:

el grado y tipo de dificultad que experimente cada estudiante a la hora de aprender a utilizar el artículo español dependerá en gran medida de las características de su lengua materna. Asímismo, si tenemos en cuenta que se trata de una forma gramatical con contenido semántico altamente abstracto, la necesidad de un enfoque contrastivo se hace todavía más evidente: el profesor de ELE que sepa, por ejemplo, que frases como Compré mesa o Conocí madre de Juan resultan totalmente naturales en muchas lenguas del mundo sabrá orientar mejor a los alumnos que son hablantes nativos de esas lenguas (Morimoto, 2011: 6).

Evidentemente, este enfoque contrastivo no tiene por qué hacerse siempre explícito en el aula, pues ello podría llegar a ocasionar problemas en algunos contextos de enseñanza como, por ejemplo, en aquellos donde confluyen alumnos (o aprendientes) procedentes de diversas partes del mundo cuya única lengua común es la lengua meta que están aprendiendo en el aula. Sin embargo, creemos que puede ser un buen punto de partida para afrontar la 
didáctica de cualquier contenido en la enseñanza de segundas lenguas, especialmente - como señala Morimoto - cuando se trata de contenidos cuyo significado es excesivamente abstracto como es el caso del artículo. La pregunta clave en el ámbito de E/LE sería: ¿qué particularidades tiene, en el sistema del español, el contenido en cuestión que lo diferencian de su comportamiento o significado en otros sistemas de lengua?

En el caso del artículo, nosotros destacamos dos particularidades:

a) El hecho de que el sistema del español tiene una categoría gramatical (el/la/los/las) que muchas lenguas eslavas y orientales no tienen:

\begin{tabular}{|l|l|}
\hline ESLOVENO & ESPAÑOL \\
\hline$\underline{\text { Učitelj ni prišel }}$ & $\begin{array}{l}\text { *Profesor no ha llegado } \\
\underline{\text { El profesor no ha llegado }}\end{array}$ \\
\hline
\end{tabular}

b) Y el hecho de que, en español, a diferencia de lo que ocurre en lenguas germánicas como el inglés o el alemán, no podemos producir expresiones genéricas con plurales y continuos escuetos: ${ }^{12}$

\begin{tabular}{|c|c|}
\hline INGLÉS & ESPAÑOL \\
\hline Tigers hunt by night ${ }^{1}$ & $\begin{array}{l}\text { *Tigres cazan por la noche } \\
\text { Los tigres cazan por la noche }\end{array}$ \\
\hline Love is blind ${ }^{2}$ & $\begin{array}{l}\text { *Amor es ciego } \\
\text { El amor es ciego }\end{array}$ \\
\hline
\end{tabular}

Como vemos, ambos hechos destacan las limitaciones que afectan a los llamados 'nombres escuetos' (es decir, las expresiones nominales sin determinante) en español, de manera que consideramos necesario focalizar nuestra atención en estas expresiones antes de abordar los contrastes que pueda haber entre ellas y los artículos el/la/los/las y un/una/unos/unas.

\section{La visión del 'nombre común escueto' en el panorama hispánico}

El tratamiento que recibe la categoría del nombre en el panorama hispánico se basa en el contraste que se establece entre el 'nombre común' y el 'nombre propio':

1 Ejemplo tomado de Radden y Dirven, 2007: 107.

2 Ejemplo tomado de Morimoto, 2011: 75. 
[...] el nombre propio puede llamarse nombre identificador: identifica, sin posible ambigüedad en una situación dada, una realidad determinada. En cambio, el nombre común no identifica realidades, sino que las clasifica diferencialmente respecto de otras: al decir bebo vino, se quiere indicar que se bebe algo que pertenece a la clase o especie de realidades llamadas 'vino'. Se podría llamar nombre clasificador" (Alarcos, 1980: 233)

Como vemos, al nombre propio se le atribuye un valor identificador, mientras que al nombre común se le atribuye un valor clasificador ${ }^{3}$. Del valor identificador que se atribuye al nombre propio se deriva un valor referencial, mientras que del valor clasificador que se atribuye al nombre común se deriva una falta de valor referencial. Por eso, se destaca la siguiente idea: «Aunque el nombre común establece la pertenencia de las entidades a ciertas clases, lo cierto es que él solo, aislado del sintagma que forma, no denota individuos, frente a lo que sucede con el propio» (Bosque, 1999: 6). Esta idea es enormemente relevante porque sostener que el nombre común «no denota individuos», es decir, que no remite a ninguna entidad perteneciente a la clase que denota su significado sino que se limita a señalar «la pertenencia de las entidades a ciertas clases» equivale, en nuestra opinión, a desposeerlo de su naturaleza nominal para atribuirle una naturaleza relacional propia de otras categorías gramaticales (verbos, adjetivos o adverbios) $)^{4}$.

Por otro lado, conviene tener en cuenta otras dos importantes diferencias que cabe hacer entre los nombres comunes: por un lado, la que distingue los nombres continuos (o incontables) de los discontinuos (o contables) ${ }^{5} \mathrm{y}$, por otro

3 Esta idea no es exclusiva de Alarcos, pues también la destacan otras fuentes. Vid. Laca, 1999: 894-895; Bosque, 1999: 5-6 y R. A. E., 2009, I: 794.

4 Aquí nos basamos en el modo en que Langacker identifica las diferentes categorías gramaticales, diferenciando aquellas que designan o perfilan una «cosa» (los nombres o expresiones nominales) de aquellas otras que designan o perfilan una «relación» entre varios participantes (los verbos o expresiones verbales, los adjetivos o complementos modificadores, los adverbios o locuciones adverbiales y las preposiciones o complementos preposicionales). Vid. Langacker, 2008: 93-127.

5 En principio, la naturaleza discontinua (contable) o continua (incontable) de un nombre depende de su significado, en el sentido de que los nombres que designan individuos u objetos de carácter físico o material que son contables debido a su forma claramente delimitada en el espacio se consideran nombres discontinuos (o contables), mientras que los que designan sustancias, materias o entidades abstractas que no son contables debido a su forma no delimitada y/o abstracta se consideran nombres continuos (o incontables). Ahora bien, conviene tener en cuenta que, en el nivel 
lado, la que distingue los singulares de los plurales ${ }^{6}$. Estas diferencias son importantes debido a las consecuencias sintácticas que tienen ya que, como indican numerosas fuentes, el nombre discontinuo singular escueto parece incapaz de funcionar como sujeto, objeto directo y atributo:

1. * Profesor no ba llegado

2. * Compré libro

3. *Esto es $\underline{\text { libro }}{ }^{7}$

Mientras que, tanto los continuos (siempre singulares) como los plurales escuetos, pueden desempeñar estas funciones sin mayores problemas:

\section{Han llegado profesores}

5. Cae agua

\section{Compré libros}

7. Necesito sal

\section{Esto son libros \\ 9. Esto es sal}

La primera cuestión que nos planteamos es, por tanto, cuáles son las razones que limitan las capacidades sintácticas del nombre discontinuo singular escueto. $\mathrm{Y}$ es que, aunque las fuentes consultadas reconocen las limitaciones que afectan a este tipo de nombres, ninguna de ellas ofrece una razón que pueda justificarlas.

sintáctico y discursivo, cualquier nombre discontinuo puede concebirse como continuo (por ejemplo, en Hoy comemos conejo el nombre «conejo» no se interpreta como «conejo» sino como carne de conejo») y cualquier nombre continuo puede concebirse como discontinuo: Queremos tres cervezas (es decir, «tres \{vasos/botellas/botes\} de cerveza»), Tenemos diversas cervezas (es decir, «diversas clases de cerveza»), Tenemos cervezas (el nombre aquí puede interpretarse tanto en el sentido de «\{́botellas/botes\} de cerveza» como en el sentido de « clases de cerveza»).

6 Todos los plurales se conciben como nombres discontinuos o contables, incluidos aquellos que proceden de nombres continuos o incontables (ej. cervezas, alegrías), porque la pluralización implica la posibilidad de delimitar y diferenciar un número $n$ de ejemplares o clases. Por ello, los continuos siempre son singulares.

7 Adviértase que esto también ocurre en inglés (*Teacher didn't come / I bought book /*This is

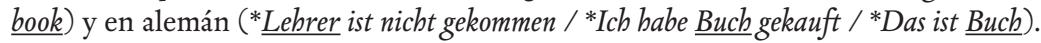




\section{El nombre discontinuo singular escueto y su falta de valor referencial y cuantificador}

En el panorama hispánico se considera que el nombre discontinuo singular escueto -como el resto de nombres escuetos- se caracteriza por su valor 'clasificador' de carácter predicativo y por su falta de valor tanto referencial como cuantificador. En la bibliografía consultada se da pormenorizada cuenta de los diferentes contextos sintácticos donde pueden aparecer los discontinuos singulares escuetos pero, de momento, nos limitaremos a señalar únicamente los más paradigmáticos, donde el carácter predicativo del nombre se deriva de su integración en lo que se llama un 'predicado complejo'.

En primer lugar, entre los llamados 'predicados complejos' destaca el caso de las locuciones verbales, las cuales:

son prácticamente equivalentes, por su semántica, a verbos simples, como por ejemplo bacer frente, bacer pie, echar mano, sentar cabeza, tomar nota, bacer fuego, bacer juego, dar parte, formar parte, tomar parte, dar lugar y tener lugar. En algunos casos, el sustantivo en cuestión es una nominalización de un verbo, como en dar \{alcance/ aviso/ cabida/ comienzo / muerte/ permiso/vuelta\} o bien bacer \{abandono/ entregas. (Laca, 1999: 920)

Pero, según Leonetti, «el fenómeno no está limitado a casos de lexicalización con núcleos verbales, sino que es productivo y se extiende a las combinaciones de preposición y nombre (en broma, a mano, de verdad, por teléfono, en conformidad con, a pesar de, a fin de)» (Leonetti, 1999: 33). Bosque coincide, en este sentido, con Leonetti y, por eso, incluye los complementos preposicionales constituidos por nombres escuetos entre los 'predicados complejos' y considera que, en estos casos, el nombre se incorpora a la preposición para conformar expresiones de carácter adverbial (comer algo con cucbara, abrir o cerrar algo con llave, hacer algo a mano, ir o viajar en coche, hablar por teléfono, etc.) $)^{8}$ adjetival (atleta de circo, artículo de periódico, mesa de cocina, etc.) ${ }^{9}$. En-

8 Vid. Bosque, 1996: 49-54.

9 «Es tradicional la idea de que entre estos complementos restrictivos, unos coexisten paradigmáticamente con verdaderos adjetivos relacionales (atleta de circo/atleta circense; artículo de periódico/artículo periodístico), mientras que otros no lo hacen, bien porque no existen los adjetivos correspondientes, bien porque existen pero están restringidos a otros contextos (peligro de guerra; mesa de cocina, etc.)» (Bosque, 1996: 55 ). 
tre estos complementos también se mencionan las expresiones lexicalizadas que funcionan como adverbios de lugar tales como estar en \{casa/prisión/cubierta/clase/misa/cama\}, ir a \{́casa/prisión/cubierta/clase/misa\}, etc. que, según Laca, no designan «simplemente un lugar físico, sino un estado, condición o actividad particular» (Laca, 1999: 922).

Como vemos, todos estos casos tienen una característica en común y es que, en ellos, el nombre no funciona como una expresión nominal sino como parte de una construcción de carácter verbal (en las locuciones verbales) o adverbial (en los complementos preposicionales). En nuestra opinión, esta característica está estrechamente vinculada al hecho de que, en estos casos, el nombre no hace referencia a ninguna entidad ni tampoco ofrece idea de cuantificación alguna sobre aquello que designa, de manera que carece tanto de valor referencial como de valor cuantificador.

A nuestro juicio, una expresión es referencial cuando aquello que designa puede ser retomado en el contexto por un pronombre relativo (que, quien/es, el/la/ los/las cual/es, el/la/los/las que, cuyo/a/s) o servir como antecedente de una expresión anafórica, ya sea ésta un pronombre anafórico sensible a los rasgos de género y número del nombre (él/ella; lo/la/s) o un verbo cuyo sujeto elíptico sea el mismo referente al que refiere la expresión nominal.

Si aplicamos esta prueba a cualquiera de las expresiones mencionadas hasta ahora, observamos que los nombres escuetos que participan en ellas carecen de valor referencial, pues no permiten enunciados como los siguientes:

10. *Tomé nota y la dejé en la mesa.

11. *No le bagas juego que sea aburrido.

12. * La llamaré por teléfono que está en el comedor.

13. * Todas ellas eran atletas de circo que ya no existe.

14. * Ricardo y Juan tienen que ir a prisión que está en el sur.

$15 .{ }^{*}$ Viajaremos en tren que atraviesa paisajes deshmbrantes.

En relación con la falta de valor cuantificador de estos nombres, advertimos dos hechos significativos que están relacionados con el carácter más o menos lexicalizado de las expresiones que conforman. Y es que, por un lado, las expresiones más fuertemente lexicalizadas impiden la pluralización del nombre (*llamar por teléfonos, *escribir a manos, *dar muertes, *hacer pies, etc.); y, por otro lado, las expresiones menos lexicalizadas no garantizan la unidad de lo 
designado en el sentido de que enunciados como eran atletas de circo, tienen que ir a prisión o viajaremos en tren no implican que se trate de un único circo, una única prisión o un único tren respectivamente.

Por otro lado, conviene hacer notar que estos últimos casos admiten pluralización:

16. Ricardo y Juan tienen que ir a prisiones que están en el sur.

17. Todas ellas eran atletas de circos que ya no existen.

18. Viajaremos en trenes que atraviesan paisajes deslumbrantes.

Como vemos, aquí los plurales sí tienen un valor referencial, pues aquello que designan puede ser retomado por un pronombre relativo para introducir nueva información al respecto, y también tienen un valor cuantificador, pues resulta evidente que aluden, respectivamente, a más de una prisión, más de un circo y más de un tren.

Estas observaciones nos hacen pensar que el valor cuantificador de una expresión nominal está estrechamente vinculado a su valor referencial y, además, nos llevan a plantearnos si acaso los plurales y continuos escuetos también constituyen expresiones referenciales y cuantificadas cuando funcionan como sujeto, objeto directo o atributo.

De momento, concentrémonos únicamente en su posible valor referencial:

4'. Han llegado profesores. ¿Los has visto?

5'. Cae agua. Parece que viene del piso de arriba.

6. Compré libros que estaban de oferta.

7’. Necesito sal que sea baja en yodo.

8'. Esto son libros que quiero leer este verano.

9'. Esto es sal. ¿La puedes poner en la mesa, por favor?

Como vemos, parece que estos nombres sí tienen valor referencial y, de hecho, pensamos que es precisamente este valor (asociado, como veremos, a su valor cuantificador) lo que les permite desempeñar las citadas funciones sintácticas con bastante libertad. 
Por la misma razón, consideramos que es la falta de valor referencial y cuantificador del discontinuo singular escueto lo que explica su incapacidad para desempeñar tales funciones e imposibilita enunciados como:

1. * Profesor no ba llegado

2. * Compré libro

3. *Esto es $\underline{\text { libro }}{ }^{10}$

PRIMERA CONCLUSIÓN: Los nombres discontinuos singulares escuetos (es decir, sin determinante) no tienen valor referencial ni cuantificador $y$, por tanto, no pueden servir para designar entidades de ninguna clase. Es por eso que oraciones como Compré mesa o Conocí madre de Juan (Marimoto, 2011: 6) no son posibles en español. Sin embargo, los plurales y continuos escuetos sí tienen un valor referencial que les permite hacer referencia a entidades: Compré mesas, Conocígente.

[Esta idea es, a nuestro juicio, una de las principales ideas que conviene destacar en el aula de E/LE, especialmente cuando la enseñanza se dirige a comunidades de hablantes cuya lengua materna carece de la categoría del artículo.]

\section{El valor cuantificador (y referencial) de plurales y continuos escuetos}

Aunque las lenguas germánicas sí tienen el contraste entre el artículo determinado o definido (the en inglés, der/das/die en alemán ${ }^{11}$ ) y el indeterminado o indefinido ( $a / a n$ en inglés, einer/ein/eine en alemán ${ }^{12}$ ), los nombres comunes escuetos no funcionan en ellas de la misma manera que funcionan en español:

10 Como veremos más adelante, en realidad creemos que un enunciado como *Esto es libro no es posible en español porque el nombre 'libro' no cumple las condiciones necesarias para funcionar como atributo.

11 Der/die/das son los artículos correspondientes al caso nominativo, de manera que para completar el paradigma de los artículos alemanes habría que añadir las formas correspondientes al resto de casos.

12 Einer/ein/eine también son los artículos que corresponden al caso nominativo, así que habría que incluir los correspondientes al resto de casos para completar el paradigma. 


\begin{tabular}{|c|c|c|c|}
\hline & ALEMÁN & INGLÉS & ESPAÑOL \\
\hline \multirow[t]{2}{*}{$\begin{array}{l}\text { expresiones } \\
\text { genéricas }\end{array}$} & Tiger jagen in der Nacht & Tigers hunt by night ${ }^{13}$ & $\begin{array}{l}{ }^{*} \text { Tigres cazan por la } \\
\text { noche } \\
\text { Los tigres cazan por la } \\
\text { noche }\end{array}$ \\
\hline & Ich mag Bier & I like beer & $\begin{array}{l}\text { *Me gusta cerveza } \\
\text { Me gusta la cerveza }\end{array}$ \\
\hline \multirow{2}{*}{$\begin{array}{l}\text { expresiones } \\
\text { no } \\
\text { genéricas }\end{array}$} & $\begin{array}{l}\text { Wir sind hier um Vögel } \\
\text { zu sehen }\end{array}$ & $\begin{array}{l}\text { We're here to see } \\
\text { birds }^{14}\end{array}$ & $\begin{array}{l}\text { Estamos aquí para ver } \\
\text { pájaros }\end{array}$ \\
\hline & $\begin{array}{l}\text { Es gibt Bier im } \\
\text { Kühlschrank }\end{array}$ & $\begin{array}{l}\text { There's beer in the } \\
\text { fridge }^{15}\end{array}$ & $\begin{array}{l}\text { Hay cerveza en la ne- } \\
\text { vera }\end{array}$ \\
\hline
\end{tabular}

Como vemos ( $\mathrm{y}$ ya hemos anunciado anteriormente), la diferencia radica en las expresiones genéricas, las cuales se construyen en inglés y alemán con plurales y continuos escuetos, mientras que en español requieren el artículo determinado. Ahora bien, las expresiones no genéricas funcionan, como puede observarse, de la misma manera en alemán, inglés y español.

En el marco de la gramática cognitiva, se considera que: a) los plurales y continuos escuetos tienen, al menos en inglés, un valor referencial y cuantificador que se representa mediante el símbolo $\emptyset$, y b) su valor cuantificador es extremadamente difuso, pues estos nombres no pueden expresar cantidades cuantitativamente delimitadas por sí mismos, ya que pueden designar desde 'más de un' ejemplar (o una cantidad indeterminada de materia) hasta 'todos/ as' los ejemplares de la especie (o 'toda' la materia en tanto especie) ${ }^{16}$. Ahora bien, el contexto oracional, discursivo o situacional sí que puede delimitar (e incluso determinar de alguna forma) la cantidad referida. De lo contrario, no podríamos distinguir el sentido genérico del no genérico. Langacker alude al papel que desempeña el contexto oracional a través de un ejemplo:

For instance, in the sentence Joyce ate ice cream yesterday the mass designated by the object nominal is bounded through

13 Ejemplo tomado de Radden y Dirven, 2007: 107.

14 Ejemplo tomado de White, 2010: 71 y 77.

15 Ejemplo tomado de White, 2010: 173.

16 Según Radden y Dirven, «the indefiniteness of the zero form is fully indeterminate between its endpoints more than one and all» (Radden y Dirven, 2007: 92). Por eso, Langacker señala lo siguiente en relación con el 'artículo $\emptyset$ ': «With respect to all three parameters of its meaning - indefiniteness, the unboundedness of a mass, and unspecificity in regard to size - Ø's value can be described as one of diffuseness and the absence of precise delimitation» (Langacker, 1991: 149). 
the interaction of all the other constituents: it is limited to ice cream that was in existence yesterday, and of that to quantities a single person can consume in one day. (Langacker, 1987: 204) ${ }^{17}$.

Por el contrario, en el panorama hispánico, la mayor parte de los trabajos que hemos consultado coinciden en señalar que los nombres escuetos no sólo carecen de valor referencial sino que también carecen de valor cuantificador; de manera que, por lo general, se rechaza la idea de que pueda operar un elemento como el 'artículo cero' (o 'artículo $\emptyset$ '). Según esta visión, la falta de valor cuantificador de los nombres escuetos se relaciona (y justifica) con la idea de que "denotan entidades no delimitadas o amorfas" (Laca, 1999: 904) porque «carecen de la posibilidad de designar colecciones «cerradas» de elementos o bien grupos de elementos concebibles como unidad» (Laca, 1996: 243-244) ${ }^{18}$.

Sin embargo, nosotros creemos que esta supuesta 'falta de delimitación' no es sino una 'indeterminación cuantitativa', al menos en el caso de los plurales y continuos escuetos. Y es que, en español, los plurales y continuos escuetos sí aluden por sí mismos a cantidades delimitadas, ya que - a diferencia de sus equivalentes en inglés o alemán - queda descartada la posibilidad de que se refieran a la totalidad de la especie, de manera que sólo pueden ser interpretados como referencias a una parte de esa totalidad. Por eso, pensamos que tienen un valor cuantificador de carácter partitivo. Pero, por otro lado, los plurales y continuos escuetos del español coinciden con los del inglés en el hecho de que también aluden a cantidades indeterminadas, de manera que sólo gracias al contexto podemos hacernos una idea aproximada de la cantidad expresada.

He aquí algunos ejemplos que ilustran nuestra propuesta:

4'. Han llegado profesores. ¿Los has visto?

19. Ha caído agua en el patio. Habrá que recogerla.

20. Hoy compré libros. Todavía los llevo en la mocbila.

21. Tenemos sal. Abora la traigo.

22. Estamos aquí para ver pájaros y fotografiarlos.

17 White apunta hacia la misma idea cuando, a propósito del ejemplo There's beer in the fridge (White, 2010: 71), indica: «Now obviously, there can only be a limited amount of beer in any given refrigerator» (White, 2010: 72).

Vid. Laca, 1999: 904 y 1996: 244-246; R.A.E., 2009, I: 1.147-1.149 y Bosque, 1996: 30-34. 
23. Hay cerveza en la nevera, pero la be metido bace muy poco.

24. Esto son libros, pero no sé dónde ponerlos.

9’. Esto es sal. ¿LLa puedes poner en la mesa, por favor?

Como vemos, los nombres subrayados pueden interpretarse como cantidades indeterminadas de profesores, agua, libros, sal, pájaros y cerveza; pero, al mismo tiempo, como cantidades delimitadas, pues es evidente que no constituyen expresiones genéricas. Por otro lado, en estos ejemplos llama la atención el hecho de que las referencias que realizan los pronombres anafóricos (los, la) son determinadas: en 4', el pronombre los hace referencia al conjunto determinado (y total) de profesores que han 1legado; en 19, el pronombre la hace referencia a la cantidad determinada (y total) de agua que habrá que recoger; en 20 , el pronombre los se refiere a la cantidad determinada (y total) de libros recién comprados, etc. A nuestro entender, este fenómeno demuestra hasta qué punto el contexto oracional puede contribuir a la hora de 'determinar', de alguna manera, las cantidades aludidas.

Ahora bien, el hecho de que los plurales y continuos refieran a cantidades indeterminadas también limita sus capacidades sintácticas, sobre todo, a la hora de funcionar como sujetos.

En primer lugar, conviene destacar que no pueden funcionar como sujetos preverbales a menos que se trate de referencias focalizadas ${ }^{19}$ :

25. ?? Profesores han llegado

26. ?? Agua cae

A nuestro juicio, esta restricción tiene una explicación lógica, pues en español los sujetos no pueden constituir entidades cuantitativamente indeterminadas de manera absoluta o radical. Como ya hemos visto, los continuos y plurales escuetos dependen del contexto oracional o discursivo para que la cantidad a la que aluden no resulte absolutamente indeterminada $\mathrm{y}$, de hecho, pensamos que es por eso mismo por lo que necesitan ser introducidos después del verbo, ya que es éste último el elemento que más contribuye a la hora de ofrecer una idea aproximada de la cantidad referida.

19 Los ejemplos que se ofrecen a continuación sólo serían posibles si en el contexto se entiende que profesores y agua están focalizados: Profesores ban llegado [no estudiantes]; Agua cae [otra cosa no]. 
Una segunda restricción que conviene destacar es la incompatibilidad que manifiestan los plurales y continuos escuetos en función de sujeto ante predicados (o verbos) que no ayudan a precisar de alguna forma la cantidad referida:

27. *Son muy simpáticos profesores / *Profesores son muy simpáticos

28. ${ }^{*}$ Me gusta cerveza / ${ }^{*}$ Cerveza me gusta ${ }^{20}$

SEGUNDA CONCLUSIÓN: Los plurales y continuos escuetos no sólo tienen un valor referencial que los capacita para referirse a entidades, sino que también tienen un valor cuantificador en la medida que expresan cantidades indeterminadas de las entidades aludidas. Ahora bien, conviene tener en cuenta que estas características implican dos cosas: a) estos nombres no pueden constituir jamás expresiones genéricas que hacen referencia a la totalidad de la especie y b) tampoco pueden funcionar como sujeto (especialmente en posición preverbal) con la misma facilidad con la que lo hacen las expresiones nominales introducidas por algún determinante.

\section{El nombre discontinuo singular en función de atributo y complemento directo}

Cuando abordamos el caso de los discontinuos singulares escuetos en el apartado 3 , dijimos que estos nombres no pueden funcionar ni como atributos ni como objetos directos:

2. * Compré libro

3. *Esto es libro

Sin embargo, esta restricción cuenta con importantes excepciones en español:

29. Juan es \{́scritor / bombre / ciudadano de Valencia \}?

30. Tengo \{perro / cocbe / trabajo $\}$

Cuando las fuentes consultadas abordan estos casos, destacan la idea de que los nombres escuetos tienen aquí un carácter 'predicativo' en el sentido de que «no expresan más que propiedades [...], sin especificar ninguna operación referencial o de cuantificación» (Leonetti, 1999: 24). Es decir, que en una oración como Juan es escritor, "tenemos una predicación nominal de tipo clasificativo» mediante la cual «se asigna a Juan una propiedad» $\mathrm{y}$ «se nos informa sobre la

20 Este último ejemplo sólo sería aceptable si 'cerveza' funcionara como expresión autorreferencial: ,Cerveza' me gusta [es decir, aludiendo a la palabra o al nombre, cerveza']. 


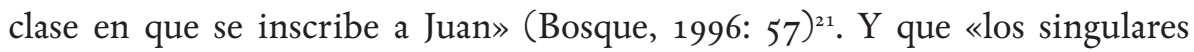
escuetos que complementan al verbo tener [...] no caracterizan tanto el objeto poseído como su poseedor «presentándolo como apto para hacer una acción determinada gracias al hecho de poseer aquel objeto»" (Bosque, 1996: 42).

Sin embargo, esta explicación resulta un tanto insuficiente si tenemos en cuenta que, en lenguas como el inglés o el alemán, no hay manera de que los nombres discontinuos singulares escuetos puedan funcionar como atributo $\mathrm{u}$ objeto directo; y que, de hecho, los enunciados equivalentes a 29 y 30 requerirían el uso del llamado 'artículo indeterminado' o 'indefinido':

29'. Juan is \{a writer / a man / a citizen of Valencia\}

29". Juan ist \{ein Schriftsteller / ein Man / ein Bürger von Valencia\}

30'. I bave $\{\underline{a d o g} / \underline{\text { a car } / \underline{a j o b}\}}$

30". Icb babe \{́einen Hund / ein Auto / eine Arbeit $\}$

Por eso, pensamos que en estos casos conviene presentar lo que - al menos para hablantes nativos de inglés o alemán - constituye un nuevo contraste: el que se da en estos contextos en español entre los nombres escuetos y las correspondientes expresiones introducidas por un/una.

Empecemos con el caso de los atributos:

\section{Luisa Valenzuela es escritora}

32. Luisa Valenzuela es una escritora

En nuestra opinión, tanto escritora como una escritora tienen aquí un carácter predicativo, pues ambas expresiones atribuyen una propiedad de clase al sujeto expresando que pertenece a la clase de «los escritores». Es más, pensamos que este carácter predicativo está estrechamente vinculado a la naturaleza adjetival que caracteriza a todos los atributos en general.

La naturaleza adjetival de los atributos se demuestra en el hecho de que sólo pueden ser reemplazados por el artículo neutro $l 0^{22}$ :

31': Luisa Valenzuela, ¡es escritora? / Sí, lo es.

32': Luisa Valenzuela, jes una escritora? / Sí, lo es.

21 Así entendido, el carácter predicativo del nombre escueto se asocia a los contextos donde funciona como 'predicado', como en los atributos, los complementos predicativos y las aposiciones. Vid. Lapesa, 1996: 126-128.

Vid. Alarcos, 1980: 235-248. 
Por ello, no creemos que aquello que caracteriza aquí al nombre escueto y lo diferencia de otras expresiones introducidas por algún determinante sea su carácter predicativo, pues se trata de una característica común a todos los atributos. De hecho, creemos que la principal diferencia entre 31 y 32 es la que concierne al valor referencial de las expresiones subrayadas:

\section{1". *Luisa Valenzuela es escritora que vive en Buenos Aires}

32". Luisa Valenzuela es una escritora que vive en Buenos Aires

Como vemos, la imposibilidad de un enunciado como 31 " demuestra que escritora no constituye una expresión referencial, mientras que la posibilidad de un enunciado como 32" demuestra que una escritora sí tiene un valor referen$\mathrm{cial}^{23}$. En realidad, la principal diferencia es que, en 31 , el hablante se limita a indicar la profesión a la que pertenece el sujeto o, dicho de otro modo, responde la pregunta «iCuál es su profesión?»; mientras que, en 32, el hablante está identificando al sujeto con un referente respondiendo a la pregunta «ن Quién es Luisa Valenzuela?’».

En conclusión, creemos que, cuando los nombres discontinuos singulares escuetos funcionan como atributos, también forman parte de un 'predicado complejo' de carácter atributivo, donde el nombre (o la expresión que conforma) funciona como un único adjetivo:

\begin{tabular}{|l|l|l|l|l|}
\hline L.Valenzuela & es & $\begin{array}{l}\text { escritora } \\
\text { mujer } \\
\text { ciudadana de } \\
\text { Buenos Aires }\end{array}$ & L.Valenzuela & es \\
\hline
\end{tabular}

Sin embargo, cuando introducimos el nombre mediante un/una, la expresión adquiere un carácter referencial de manera que no se limita a expresar una propiedad o cualidad del sujeto sino que remite a un individuo al que podemos caracterizar como y cuanto queramos:

23 Aquí conviene advertir la posibilidad de un enunciado como a) L. Valenzuela es una escritora argentina, frente a la imposibilidad de un enunciado como b) ${ }^{*} L$. Valenzuela es escritora argentina. Parece que los discontinuos singulares escuetos en función de atributo sólo admiten modificadores directamente vinculados a la propiedad que se predica, de manera que ésta pueda entenderse como una única propiedad: Es \{́ciudadano de los EE.UU./abogado de oficio/maestro de escuela/escritor de novelas históricas $\}^{\zeta}$. Sin embargo, en el ejemplo b), el adjetivo argentina también puede interpretarse como modificador del sujeto de manera que la única opción posible sería c) L. Valenzuela es escritora y es argentina. 


\begin{tabular}{|l|l|l|}
\hline L. Valenzuela es & $\begin{array}{l}\text { una escritora } \\
\text { una mujer } \\
\text { una ciudadana de Buenos Aires }\end{array}$ & $\begin{array}{l}\text { (argentina, simpática e inteligente) } \\
\text { (que vive en Buenos Aires) } \\
\text { (que escribe novelas y relatos) }\end{array}$ \\
\hline
\end{tabular}

En el caso de los nombres discontinuos singulares en función de objeto directo nos encontramos con una situación bastante similar, pero no idéntica:

33. Tengo perro

34. El botel tiene piscina

35. Hoy llevo fald ${ }^{24}$

36. Tengo un perro

37. El botel tiene una piscina

38. Hoy llevo una falda

Resulta evidente que los nombres escuetos, a diferencia de los introducidos por un/una, carecen de valor referencial:

33. *'Tengo perro que está enfermo

34'. Tengo un perro que está enfermo

35'. *El botel tiene piscina que siempre está abarrotada de gente.

36. El botel tiene una piscina que siempre está abarrotada de gente

$37 .{ }^{*}$ Hoy llevo falda que me regaló mi madre

38'. Hoy llevo una falda que me regaló mi madre

Este hecho resulta perfectamente compatible con la visión que ofrecen la mayoría de las fuentes consultadas, según las cuales el nombre escueto tiene en estos casos un carácter predicativo en la medida que sirve para atribuir propiedades o para caracterizar a alguien (o algo) como poseedor y que, por eso, funciona como parte de un 'predicado complejo' cuyo significado está vinculado a estereotipos o valores sociales:

24 Este fenómeno no se limita a los objetos directos del verbo tener sino que también puede darse con otros verbos relacionados con la posesión o uso (llevar, vestir, gastar, usar) y, como indica Laca, «se extiende a los complementos directos de verbos de adquisición u obtención (comprar coche, conseguir piso, sacar billete), o a verbos semánticamente emparentados a estos como poner(se) [...], buscar [...] o dar» (Laca, 1999: 919). 
El objeto directo conserva autonomía significativa respecto del verbo, pero la mira del hablante no se dirige hacia los seres o cosas designados, ni tampoco a su género o clase, sino a lo que el conjunto <verbo + complemento directo> representa como signo valorable, situación o categoría social, hábito, etc.: tener coche, tener casa propia, [...] se dejó barba (Lapesa, 1996: 129)25.

En conclusión, podemos decir que el nombre escueto en estos casos se entiende como parte de un 'predicado complejo' en el que, a diferencia de lo que ocurre cuando el nombre es introducido por un/una, no se resalta el objeto en cuestión como referente ni como unidad sino el valor social que representa el hecho de tenerlo (o no), llevarlo (o no), conseguirlo (o no), etc.:

\begin{tabular}{|c|c|}
\hline Tengo & perro \\
\hline Tengo & un perro \\
\hline
\end{tabular}

Ahora bien, la «autonomía significativa respecto del verbo» que, según Lapesa, caracteriza a los objetos directos hace que en estos casos la diferencia sea mucho más sutil que en el caso de los atributos. De hecho, aquí siempre hay posibilidad de interpretar lo designado por el nombre escueto como una expresión referencial:

39. ¿Tienes perro? / Sí, ¿puedo pasar con éll?

40. ¿El hotel tiene piscina? / Sí, pero no te la recomiendo porque siempre está abarrotada de gente.

41. ¿Hoy llevas falda? / Sí, la que me regaló mi madre.

\section{Nombres continuos y plurales escuetos no referenciales}

La propuesta que hemos presentado se ajusta al comportamiento general de los dos principales tipos de nombres escuetos: discontinuos singulares por un lado, y continuos y plurales por otro. Sin embargo, los valores que atribuimos a cada grupo no deben entenderse como valores inherentes que siempre están

25 Sin duda, estos casos responden a estereotipos culturales o sociales que favorecen la caracterización del sujeto: «Así, no se dirá Juan compró castillo o Este edificio tiene torre, salvo en entornos en los que la compra de castillos como acceso a una condición determinada o la presencia de una torre como parte de un (tipo de) edificio esté dentro de las expectativas normales» (Laca, 1999: 919). Vid. Bosque, 1996: 41-45; Leonetti, 1999: 33-34 y R.A.E., 2009, I: 1.156. 
en activo sino, más bien, como valores predominantes cuya actualización depende del contexto sintáctico, discursivo o situacional.

De hecho, el nombre discontinuo singular escueto puede tener en algunos casos tanto un valor referencial como un valor cuantificador:

42. Esto lo tiene que bacer en secretaría, que está en el tercer piso.

Como vemos, aquí el nombre secretaría funciona casi como un nombre propio que refiere a un lugar determinado, único e identificable por el oyente como tal.

Por su parte, los plurales y continuos escuetos tampoco tienen siempre un valor referencial y cuantificador:

43a. Eso es un juego de niños.

44a. ¿Llevas pendientes de oro?

Aquí ni niños ni oro tienen un valor referencial, pues no hay manera de retomar lo que designan mediante una expresión anafórica, ni siquiera con el pronombre relativo que:

43b. Eso es un juego de niños que juegan, a veces, en el parque.

$44 \mathrm{~b}$. ¿Llevas unos pendientes de oro que compraste en Estambul?

Como vemos, en 43 b es difícil interpretar niños como sujeto de la subordinada relativa porque, de hecho, ésta no caracteriza a niños sino a un juego de niños. De la misma manera, en $44 \mathrm{~b}$ lo que compraste en Estambul no es oro sino unos pendientes de oro. Por tanto, parece que en 43 y 44 los nombres subrayados sí funcionan como nombres 'clasificadores' en la medida en que se limitan a atribuir una propiedad de clase a otras entidades (a un juego y a unos pendientes, respectivamente). Pero este fenómeno no es tan propio del nombre como del adjetivo. De hecho, pensamos que oro y niños no funcionan aquí como nombres sino que, junto con la preposición $d e$, funcionan como adjetivos (de niños $=$ infantil).

Lo mismo ocurre en el caso de las locuciones verbales donde participan plurales escuetos (estar en llamas, dar vueltas, pedir cuentas, etc.) o continuos escuetos como en: "tener envidia (= envidiar), tener miedo (= temer), dar gusto (= complacer), dar pena (= apenar), poner atención (= atender) [...]" (Lapesa, 1996: 129). En estos casos el nombre tampoco funciona como una expresión de carácter o naturaleza nominal sino como parte de una expresión de carácter o naturaleza verbal. 
Por esta razón, creemos que resulta oportuno plantear la intervención del 'artículo $\emptyset^{\prime}$ en los casos donde los nombres escuetos adquieren realmente un valor referencial y cuantificador de manera que funcionan como verdaderas expresiones nominales, con el fin de diferenciarlos de aquellos otros casos donde no logran adquirir estos valores y, en consecuencia, no funcionan como expresiones nominales sino como parte de otro tipo de expresiones (verbales, adjetivales o adverbiales).

\section{Bibliografía}

Alarcos, E. (1980): «El artículo en español», «iLo fuertes que eran! », «Grupos nominales con /de/ en español»y «Español /que/». En Alarcos, E. (ed.), Estudios de gramática funcional del español, Madrid: Gredos, 223-274.

Barton, J. (1961): «The Application of the Article in English». En International Conference on Machine Translation of Languages and Applied Language Analysis, Teddington, UK: National Physical Laboratory, 112-118.

Bosque, I. (1996): «Por qué determinados sustantivos no son sustantivos determinados. Repaso y balance». En Bosque, I. (ed.), El sustantivo sin determinación. La ausencia de determinante en la lengua española, Madrid: Visor Libros, 13-119.

Bosque, I. (1999): «El nombre común». En Bosque, I. y Demonte, V. (eds.), Gramática descriptiva de la lengua española, Vol. I, Madrid: Espasa-Calpe, 3-70.

Laca, B. (1999): «Presencia y ausencia de determinante». En Bosque, I. y Demonte, V. (eds.), Gramática descriptiva de la lengua española, Vol. I. Madrid: Espasa-Calpe, 891-928.

Laca, B. (1999): «Acerca de la semántica de los plurales escuetos en español». En Bosque, I. y Demonte, V. (eds.), Gramática descriptiva de la lengua española, Vol. I. Madrid: Espasa-Calpe, 241-268.

Langacker, R. (2008): Cognitive Grammar. A Basic Introduction. New York: Oxford University Press

Lapesa, R. (1999): «El sustantivo sin actualizador en español». En Bosque,

I. y Demonte, V. (eds.), Gramática descriptiva de la lengua española, Vol. I. Madrid: Espasa-Calpe, 121-137.

Leonetti, M. (1999): Los determinantes. Madrid: Arco Libros.

Morimoto, Y. (2011): El artículo en español. Barcelona/Madrid: Edhasa (Castalia) 
Radden, G. y Dirven, R. (2007): Cognitive English Grammar. Amsterdam (Holanda)/Philadelphia (EE.UU.): John Benjamin Publishing Company.

R.A.E. (2009): Nueva Gramática de la Lengua Española, Vol. I, Madrid: EspasaLibros, 1.143-1.160.

White, B. J. (2010): In Search of Systematicity: A Conceptual Framework for the English Article System. Michigan: Michigan State University, UMI/ ProQuest. 


\section{Sonia Montero Gálvez}

Columbia University, New York

\section{Bare nouns in Spanish}

Keywords: Bare nouns, mass/count noun, singular/plural, predicative value, referential value, quantification's value, nominal expression without article, $\varnothing$ article, contrastive approach.

This article is focused on the semantic values of bare nouns in Spanish and it's intended to present a proposal that can be especially helpful for the didactic of nominal expressions in the elementary levels of SSL (Spanish as a Second Language). The main idea is that not all bare nouns work in the same way, and that we can make a basic distinction between those that are a full nominal expression profiling quantified entities (usually, singular mass nouns and plurals), and those others that are confined to be part of an adjectival, adverbial or verbal expression (usually, singular count nouns). The first group can be identified through its referential and quantification's values, whereas the second group is characterized by its lack of those values. In order to distinguish these two kinds of expressions, we can consider the participation of the ' $\emptyset$ article' in the first group, which should be understood as the guarantee of reference and quantification that provides the sintactic and situational context.

This proposal is based on the research work being developed in a doctoral thesis. It builds on the input provided by cognitive grammar, and it's supported by a contrastive approach that takes into account the main differences between the use of bare nouns in Spanish and its use in other languages. The presented approach not only departs from the view offered by the consulted sources in Spanish linguistics, but also from the own view presented in an earlier published work ${ }^{26}$.

26 Montero, S. (2011): «El artículo y otros fantasmas del nombre». RedELE, $\mathrm{n}^{\circ} 21$ (febrero, 2011). 


\section{Sonia Montero Gálvez}

Columbia University, New York

\section{Goli samostalniki in ničti člen $\varnothing$}

Ključne besede: goli samostalniki, neštevni/števni samostalniki, ednina/ množina, povedkova vloga, nanašalna vrednost, količinska vrednost, samostalniške zveze brez določila, ničti člen $\emptyset$, kontrastivni pristop

Pričujoči prispevek se osredotoča na pomenske vrednosti t. i. »golih samostalnikov « z namenom oblikovati predlog, ki bi koristno podprl poučevanje samostalniških oblik zlasti na začetnih stopnjah učenja španščine kot drugega jezika. Izhodiščna ideja v članku predpostavlja razlike med golimi samostalniki glede na njihove različne vloge, saj nekateri od njih zavzemajo vlogo pravih samostalniških zvez, ki zaznamujejo količinske vrednosti (običajno neštevni samostalniki in goli samostalniki v množini), drugi pa se omejujejo na izraze, ki nimajo samostalniških značilnosti, temveč značilnosti glagola, pridevnika ali prislova (običajno števni samostalniki v ednini). Prve opredeljujeta nanašalna in količinska vrednost, za druge pa je značilna prav odsotnost obeh vrednosti. V članku je predstavljena možnost razmejevanja med obema pojavoma $\mathrm{z}$ uvajanjem ničtega člena oz. določevalca » $\emptyset_{\ll}$ v prvi skupini golih samostalnikov, ki ga je mogoče razumeti oz. prepoznati kot zagotovilo za nanašalnost in količinskost, ki ju samostalnik pridobi iz stavčnega in diskurzivnega sobesedila oz. iz položajskega konteksta.

Predlog izhaja iz raziskovalnega dela za doktorsko disertacijo in temelji na dognanjih kognitivne slovnice ter na kontrastivnem pristopu, ki upošteva najpomembnejše razlike $\mathrm{v}$ rabi golih samostalnikov $\mathrm{v}$ španščini in drugih jezikih. Predstavljeni pristop ne izhaja samo iz stališč španskih jezikoslovcev, na katere se opiramo, temveč tudi iz našega lastnega stališča, predstavljenega v objavljeni razpravi iz leta $2011 .{ }^{27}$

27 Montero, S. (2011): «El artículo y otros fantasmas del nombre». RedELE, nº 21 (febrero, 2011). 